\title{
Prognostic Value of Estimated Glomerular Filtration Rate 3-6 Months after Percutaneous Coronary Intervention
}

\author{
Won Jik Lee ${ }^{a}$ Dong-Bin Kim ${ }^{b}$ Sung-Ho Her ${ }^{c}$ Chul Soo Park ${ }^{d}$ Jong-Min Lee ${ }^{e}$ \\ Hee-Yeol Kim ${ }^{b}$ Wook Sung Chung ${ }^{f}$
}

\begin{abstract}
a Department of Cardiology, College of Medicine, Incheon St. Mary's Hospital, The Catholic University of Korea, Incheon, Republic of Korea; ${ }^{b}$ Department of Cardiology, College of Medicine, Bucheon St. Mary's Hospital, The Catholic University of Korea, Bucheon, Republic of Korea; ' ${ }^{\circ}$ epartment of Cardiology, College of Medicine, Daejeon St. Mary's Hospital, The Catholic University of Korea, Daejeon, Republic of Korea; ${ }^{\mathrm{d}}$ Department of Cardiology, College of Medicine, Yeouido St. Mary's Hospital, The Catholic University of Korea, Seoul, Republic of Korea; e Department of Cardiology, College of Medicine, Uijeongbu St. Mary's Hospital, The Catholic University of Korea, Uijeongbu, Republic of Korea; ${ }^{\mathrm{f}}$ Department of Cardiology, College of Medicine, Seoul St. Mary's Hospital, The Catholic University of Korea, Seoul, Republic of Korea
\end{abstract}

\section{Keywords}

Renal insufficiency · Drug-eluting stent · Prognosis

\begin{abstract}
Background: The prognostic significance of follow-up $(\mathrm{f} / \mathrm{u})$ renal function for patients undergoing percutaneous coronary intervention $(\mathrm{PCl})$ remains unknown. This study sought to investigate the prognostic implications of $\mathrm{f} / \mathrm{u}$ renal function in patients undergoing $\mathrm{PCl}$. Methods: A drug-eluting stent registry was used. We divided patients into 4 groups according to the change in the estimated glomerular filtration rate (eGFR) before $\mathrm{PCl}$ and 3-6 months after $\mathrm{PCl}$. Patients with normal pre-PCl eGFR and f/u eGFR were assigned to group 1. Those with normal pre-PCl eGFR and abnormal f/u eGFR were assigned to group 2. Patients with abnormal pre-PCI eGFR and normal f/u eGFR were assigned to group 3. Patients with abnormal pre-PCl eGFR and f/u eGFR were allocated into group 4. Results: A total of 4,899 PCl patients were enrolled. The death rate in group 1, 2, 3, and 4 at 3 years was $2,11,4$, and $9 \%$, respectively. This showed significant
\end{abstract}

karger@karger.com www.karger.com/crm

Karger $\frac{1}{\%}$

GOPEN ACCESS
(C) 2020 The Author(s)

Published by S. Karger AG, Basel

This is an Open Access article licensed under the Creative Commons Attribution-NonCommercial-4.0 International License (CC BY-NC) (http://www.karger.com/Services/OpenAccessLicense), applicable to the online version of the article only. Usage and distribution for commercial purposes requires written permission. differences between groups, except between groups 2 and 4. The prognosis of a group with aggravation from normal renal function was worse than that of a group with recovery from abnormal renal function. A prediction model that combines clinical risk factors and f/u eGFR has more power for predicting clinical outcomes than a combination of clinical risk factors and pre-PCl eGFR. Conclusion: Post-PCl eGFR was more accurate for predicting patient outcomes than pre-PCI eGFR.

(c) 2020 The Author(s)

Published by S. Karger AG, Basel

\section{Introduction}

Renal impairment is a prevalent comorbid risk factor among patients with obstructive coronary artery disease undergoing percutaneous coronary intervention (PCI) [1]. Renal dysfunction is associated with systemic inflammation, endothelial dysfunction, accelerated atherosclerosis, and enhanced thrombogenicity, thus increasing the risk for cardiovascular and cerebrovascular ischemic 
events [2]. Chronic kidney disease (CKD) is associated with adverse outcomes in those with existing cardiovascular disease [3]. However, most previous research has used the pre-PCI renal function to determine the prognosis of patients. Few studies have used the follow-up (f/u) renal function determined $\geq 3$ months after PCI to evaluate the prognosis of patients. The glomerular filtration rate (GFR) is a sensitive measure of kidney function, but it is seldom measured directly in practice. Instead, the estimated (e)GFR is calculated using a formula, e.g., that from the Modification of Diet in Renal Disease (MDRD) study [4]. The objective of this study was to investigate the prognostic implication of $\mathrm{f} / \mathrm{u}$ renal function in patients undergoing PCI. We also evaluated predictive factors for changes in renal function after PCI.

\section{Methods}

\section{Study Population}

This investigation was a retrospective, multicenter, observational study. Subjects were recruited from the cardiovascular catheterization database of Catholic Medical Center (Seoul, South Korea), consisting of 8 hospitals.

Serum creatinine was measured before index PCI and 3-6 months after index PCI. Patients were divided into 4 groups according to eGFR change pre-PCI and 3-6 months after PCI. Patients with normal pre-PCI eGFR and f/u eGFR were assigned to group 1. Those with normal pre-PCI eGFR and abnormal f/u eGFR were assigned to group 2. Patients with abnormal pre-PCI eGFR and normal f/u eGFR were assigned to group 3. Patients with abnormal pre-PCI eGFR and f/u eGFR were assigned to group 4.

\section{Exclusion Criteria}

Patients on dialysis before hospital admission, a f/u period of $<3$ months, or had no available data were excluded.

\section{Definitions}

Abnormal eGFR was considered based on a baseline eGFR $<60$ $\mathrm{mL} / \mathrm{min} / 1.73 \mathrm{~m}^{2}$ according to the MDRD equation [4]. CKD was defined as eGFR $<60 \mathrm{~mL} / \mathrm{min} / 1.73 \mathrm{~m}^{2}$ for 3 months; this is the accepted cutoff value in the guidelines of the National Kidney Foundation Kidney Disease Outcomes Quality Initiative [5].

Patients were considered to have diabetes mellitus (DM) if they took DM medication, their fasting plasma glucose concentration was $\geq 126 \mathrm{mg} / \mathrm{dL}$, or their 2 casual plasma glucose concentrations were $\geq 200 \mathrm{mg} / \mathrm{dL}$. Systemic hypertension was defined as taking hypertension medication, systolic blood pressure (SBP) $\geq 140 \mathrm{~mm}$ $\mathrm{Hg}$, or diastolic pressure $\geq 90 \mathrm{~mm} \mathrm{Hg}$. Hyperlipidemia was defined as taking a statin or a low-density lipoprotein cholesterol value $\geq 140 \mathrm{mg} / \mathrm{dL}$. Smokers were defined as those who were either current or past smokers. Cerebrovascular accidents included both ischemic and hemorrhagic events. Shock was defined as SBP $<90$ $\mathrm{mm} \mathrm{Hg}$ for $>30 \mathrm{~min}$ or the need for supportive management to maintain SBP at $>90 \mathrm{~mm} \mathrm{Hg}$.
Cardiac Intervention Techniques/Procedures

Each operator performed all procedures using standard cardiac interventional techniques. Patients who had not previously taken antiplatelet agents were administered loading doses of aspirin (300 mg) and clopidogrel (300-600 mg). Anticoagulation therapy during PCI was performed following current practice guidelines. All enrolled patients had PCI performed with a second-generation drug-eluting stent. The type of drug-eluting stent and glycoprotein IIb/IIIa receptor antagonist used were at the operator's discretion.

Iso-osmolar agent (iodixanol) was used in all angiography procedures. In elective PCI, patients with CKD routinely received intravenous hydration with isotonic saline solution at $1 \mathrm{~mL} / \mathrm{kg} / \mathrm{h}$ for $12 \mathrm{~h}$ before the diagnostic procedure and $12 \mathrm{~h}$ after the procedure. In emergency PCI, hydration was performed during the diagnostic procedure using isotonic saline solution and continued at a rate of $1 \mathrm{~mL} / \mathrm{kg} / \mathrm{h}$ for at least $12 \mathrm{~h}$. The operator determined the duration of dual antiplatelet therapy.

\section{Study Outcomes}

Study outcomes were all-cause death, cardiac death, recurrent myocardial infarction (MI), and target lesion revascularization (TLR). Death was considered to be of cardiac origin unless a definite noncardiac cause could be established. MI was defined as an elevation of CK-MB fraction or troponin T/troponin I higher than the upper limit of normal, with concomitant ischemic symptoms and electrocardiographic findings indicative of ischemia. TLR was defined as a repeat PCI of the lesion within $5 \mathrm{~mm}$ of stent deployment.

\section{Data Collection}

Demographic, clinical, laboratory, and angiographic data were collected using a web-based reporting system. All baseline and procedural coronary angiograms were reviewed at the core laboratory. We obtained additional information from the medical records at all 8 hospitals and through telephone contact. All outcomes were reported by the participating hospitals.

\section{Statistical Analysis}

Categorical variables are presented as numbers and percentages. They were compared using the $\chi^{2}$ test. Continuous variables are expressed as mean \pm standard deviation. They were analyzed using Student's $t$ test. Event rates were calculated based on KaplanMeier censoring estimates. The log-rank test was used to compare survival curves between groups. Hazard ratio (HR) and 95\% confidence interval (CI) were generated using Cox regression. Adjusted covariates included variables listed in Table 1 . To evaluate the independent effect of eGFR on clinical outcomes, we performed multivariable-adjusted Cox proportional hazard model analysis. The multivariate model included all parameters with a $p$ value $<0.20$ in univariate analysis. The incremental prognostic value of pre-PCI and post-PCI eGFR, in addition to clinical risk factors, was assessed using the Brier score, Harrell's C index, net reclassification improvement, and the integrated discrimination improvement index [6]. Clinical risk factors included age, sex, hypertension, DM, hyperlipidemia, a history of MI, a history of revascularization, and acute coronary syndrome. Statistical analyses were performed using $R$ statistical software v3.2.5 ( $R$ Foundation for Statistical Computing, Vienna, Austria). All tests were 2-tailed, and $p<0.05$ was considered statistically significant. 
Table 1. Baseline characteristics of study groups

\begin{tabular}{|c|c|c|c|c|c|}
\hline & $\begin{array}{l}\text { Group 1 } \\
(n=3,467)\end{array}$ & $\begin{array}{l}\text { Group 2 } \\
(n=403)\end{array}$ & $\begin{array}{l}\text { Group } 3 \\
(n=312)\end{array}$ & $\begin{array}{l}\text { Group } 4 \\
(n=717)\end{array}$ & $p$ value \\
\hline Age, years & $61 \pm 11$ & $68 \pm 9$ & $66 \pm 10$ & $70 \pm 9$ & $<0.001$ \\
\hline Diabetes mellitus & $31(1,038)$ & $43(173)$ & $40(122)$ & $57(388)$ & $<0.001$ \\
\hline Hypertension & $55(1,901)$ & $65(262)$ & $72(224)$ & $78(561)$ & $<0.001$ \\
\hline Hyperlipidemia & $49(1,711)$ & $48(192)$ & $50(155)$ & $54(387)$ & 0.111 \\
\hline Current smoker & $27(1,324)$ & $35(140)$ & $32(99)$ & $28(200)$ & $<0.001$ \\
\hline Prior PCI & $7(225)$ & $8(31)$ & $9(28)$ & $8(58)$ & 0.182 \\
\hline Prior myocardial infarction & $4(152)$ & $6(22)$ & $5(17)$ & $7(47)$ & 0.250 \\
\hline CVA history & $7(229)$ & $12(46)$ & $12(38)$ & $11(82)$ & $<0.001$ \\
\hline Prior CABG & $1(33)$ & $2(6)$ & $1(2)$ & $2(12)$ & 0.152 \\
\hline Clinical presentation & & & & & 0.004 \\
\hline \multicolumn{6}{|l|}{ eGFR } \\
\hline Pre-PCI, $\mathrm{mL} / \mathrm{min}$ & $88 \pm 32$ & $73 \pm 13$ & $53 \pm 8$ & $43 \pm 14$ & $<0.001$ \\
\hline Post-PCI (3-6 months), $\mathrm{mL} / \mathrm{min}$ & $86 \pm 21$ & $48 \pm 12$ & $76 \pm 56$ & $40 \pm 14$ & $<0.001$ \\
\hline LVEF, \% & $60 \pm 10$ & $57 \pm 13$ & $57 \pm 11$ & $56 \pm 13$ & $<0.001$ \\
\hline Cardiogenic shock & $7(243)$ & $8(32)$ & $10(31)$ & $9(65)$ & 0.093 \\
\hline
\end{tabular}

Values express \% $(n)$ or mean \pm SD. eGFR, estimated glomerular filtration rate; CABG, coronary artery bypass graft; CVA, cerebrovascular accident; LVEF, left ventricular ejection fraction; STEMI, ST-segment elevation myocardial infarction; NSTEMI, nonSTEMI; PCI, percutaneous coronary intervention.

\section{Results}

From January 2011 to December 2013, a total of 4,899 out of 5,996 consecutive patients who underwent PCI with a drug-eluting stent were included (Fig. 1). The median $\mathrm{f} / \mathrm{u}$ duration was 2.6 years (interquartile range [IQR] 1.7-3.8 years). The number of patients in groups $1,2,3$, and 4 was $3,467,403,312$, and 717 , respectively. The mean age of patients was $63 \pm 11$ years. Male comprised $64 \%$. Normal pre-PCI eGFR rate was $79 \%(3,870$ patients), and abnormal eGFR rate 3-6 months after PCI was $23 \%$ (1,120 patients). The rate of normal pre-PCI eGFR that changed to abnormal post-PCI eGFR was $10 \%$ (403 patients). The rate of recovery of abnormal pre-PCI eGFR was 30\% (312 patients).

Baseline, angiographic, procedural, and medication characteristics are summarized in Tables 1 and 2. Regarding baseline characteristics, group 1 included a significantly higher rate of young and male patients than the other groups. Group 1 also had fewer smokers, a lower prevalence of $\mathrm{DM}$, hypertension, and cerebrovascular accident (CVA) history, and higher levels of eGFR and left ventricular ejection fraction (LVEF) than other groups. Group 4 showed a higher rate of DM than other groups. In terms of procedural characteristics, the left anterior descending (LAD) artery was the most often to be treated in all 4 groups. Group 1 used a larger diameter of stents than the other groups. As discharge medication, aspirin and thienopyridine were used for nearly all patients. Of P2Y12 receptor inhibitors, clopidogrel was mainly prescribed. Angiotensin-converting-enzyme inhibitor/angiotensin II receptor blocker, beta-blocker, and statin were used in more than half of the patients in all groups.

Figure 2 demonstrates all-cause death according to renal function changes. The all-cause death rate in groups $1,2,3$, and 4 at 3 years was $2,11,4$, and $9 \%$, respectively, showing significant differences between groups except between groups 2 and 4 (group 1 vs. group 2, $p<0.001$; group 1 vs. group $3, p=0.009$; group 1 vs. group $4, \mathrm{p}<$ 0.001 ; group 2 vs. group $3, p=0.004$; group 2 vs. group 4 , $p=0.796$; group 3 vs. group $4, p=0.004)$. The cardiac death rate in groups $1,2,3$, and 4 at 3 years was $1,4,3$, and $5 \%$, respectively (group 1 vs. group $2, p<0.001$; group 1 vs. group $3, p=0.006$; group 1 vs. group $4, p<0.001$; 
Fig. 1. Schematic illustration of study cohort selection. The study population was derived from a multicenter drug-eluting stent registry. DES, drug-eluting stent; eGFR, estimated glomerular filtration rate; f/u, follow-up.

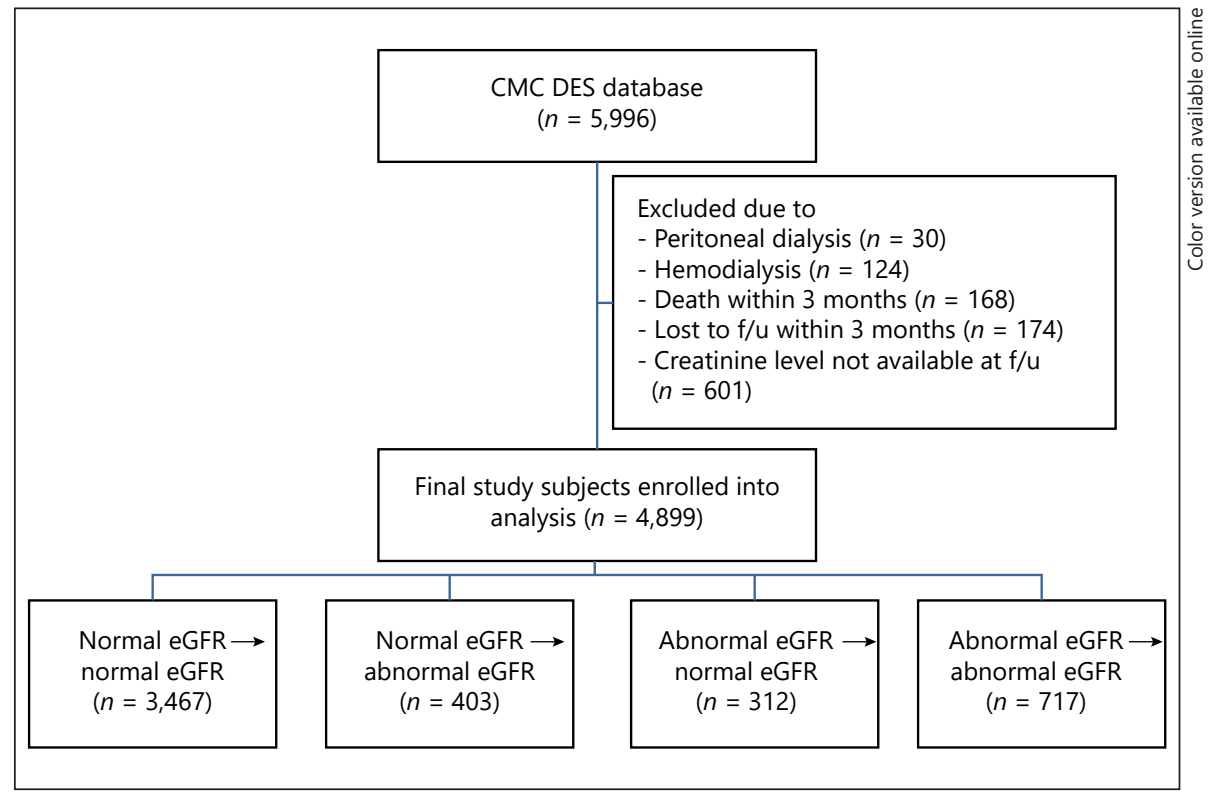

Table 2. Procedural characteristics and medication

\begin{tabular}{|c|c|c|c|c|c|}
\hline & $\begin{array}{l}\text { Group 1 } \\
(n=3,467)\end{array}$ & $\begin{array}{l}\text { Group 2 } \\
(n=403)\end{array}$ & $\begin{array}{l}\text { Group 3 } \\
(n=312)\end{array}$ & $\begin{array}{l}\text { Group 4 } \\
(n=717)\end{array}$ & $p$ value \\
\hline \multicolumn{6}{|l|}{ Artery involved } \\
\hline Left anterior descending & $75(2,610)$ & $78(313)$ & $78(244)$ & $79(569)$ & 0.081 \\
\hline Left circumflex & $48(1,665)$ & $53(213)$ & $46(142)$ & $57(408)$ & $<0.001$ \\
\hline Right & $51(1,757)$ & $55(221)$ & $52(162)$ & $61(437)$ & $<0.001$ \\
\hline Stent diameter, $\mathrm{mm}$ & $3.21 \pm 0.41$ & $3.12 \pm 0.38$ & $3.16 \pm 0.37$ & $3.11 \pm 0.37$ & $<0.001$ \\
\hline Stent length, mm & $39 \pm 25$ & $42 \pm 25$ & $38 \pm 22$ & $42 \pm 27$ & 0.001 \\
\hline \multicolumn{6}{|l|}{ Medication at discharge } \\
\hline Aspirin & $99(3,432)$ & $99(397)$ & $98(306)$ & $99(701)$ & 0.041 \\
\hline Clopidogrel & $100(3,466)$ & $100(402)$ & 99 (309) & $100(715)$ & $<0.001$ \\
\hline Beta-blocker & $67(2,312)$ & $68(273)$ & $66(207)$ & $68(485)$ & 0.936 \\
\hline
\end{tabular}

Values express $\%(n)$ or mean $\pm \mathrm{SD}$. ACEi/ARB, angiotensin-converting-enzyme inhibitor/angiotensin II receptor blocker.

group 2 vs. group 3, $p=0.310$; group 2 vs. group $4, p=$ 0.471 ; group 3 vs. group $4, p=0.083)$. There were no significant differences in recurrent $\mathrm{MI}$ rate $(2,2,4$, and $2 \%$, respectively, $p=0.142)$ and TLR rate $(15,14,17$, and $11 \%$, respectively, $p=0.179$ ). An adjusted HR for clinical outcomes showed that group 2 patients were at an excess risk of all-cause death but that their risk of cardiac death, tar- get vessel MI, and TLR were comparable to those of group 3 patients (Table 3 ).

Independent predictors of CKD progression and renal recovery by multivariable analysis are presented in Table 4 (using variables from Table 1). Old age, male, DM, a CVA history, and low LVEF were significant predictors of the development of CKD after PCI in group 1 and 


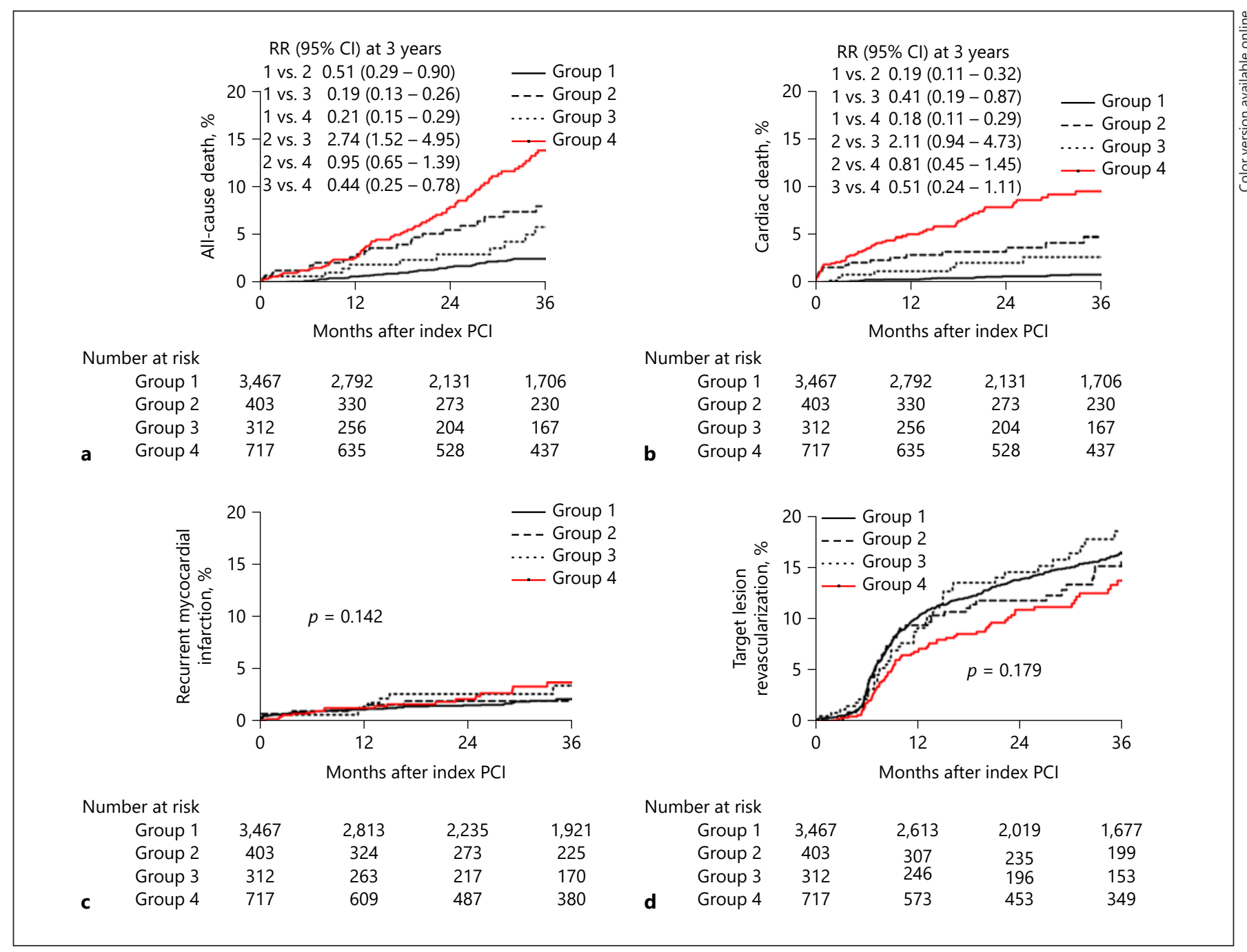

Fig. 2. Kaplan-Meier curves with cumulative hazards. a All-cause death. b Cardiac death. c Myocardial infarction. d Target lesion revascularization. All-cause death and cardiac death rates showed significant differences among groups. There were no significant differences in recurrent myocardial infarction rate or target lesion revascularization rate across the 4 groups.

Table 3. Cumulative clinical outcomes in group 2 and group 3

\begin{tabular}{|c|c|c|c|c|c|c|}
\hline & $\begin{array}{l}\text { Group } 2 \\
(n=403)\end{array}$ & $\begin{array}{l}\text { Group } 3 \\
(n=312)\end{array}$ & $\begin{array}{l}\text { Unadjusted HR } \\
(95 \% \mathrm{CI})\end{array}$ & $p$ value & $\begin{array}{l}\text { Adjusted HR } \\
(95 \% \mathrm{CI})\end{array}$ & $p$ value \\
\hline All-cause death & $11 \%(n=44)$ & $4 \%(n=14)$ & $2.36(1.29-4.31)$ & 0.002 & $2.14(1.10-4.18)$ & 0.025 \\
\hline Cardiac death & $4 \%(n=17)$ & $3 \%(n=8)$ & $1.54(0.66-3.58)$ & 0.305 & $1.77(0.70-4.52)$ & 0.231 \\
\hline Recurrent MI & $2 \%(n=10)$ & $4 \%(n=13)$ & $0.78(0.25-2.41)$ & 0.285 & $0.68(0.27-1.75)$ & 0.428 \\
\hline TLR & $14 \%(n=56)$ & $17 \%(n=54)$ & $0.83(0.57-1.20)$ & 0.212 & $0.79(0.50-1.24)$ & 0.301 \\
\hline
\end{tabular}

$\mathrm{CI}$, confidence interval; HR, hazard ratio; MI, myocardial infarction; TLR, target lesion revascularization. 
Table 4. Independent variables for renal function change after PCI

\begin{tabular}{|c|c|c|c|c|c|c|}
\hline & \multicolumn{3}{|c|}{$\begin{array}{l}\text { Occurrence of CKD after PCI in patients } \\
\text { with normal eGFR }(n=3,870)\end{array}$} & \multicolumn{3}{|c|}{$\begin{array}{l}\text { Kidney function recovery after PCI in abnormal } \\
\text { pre-PCI eGFR }(n=1,029)\end{array}$} \\
\hline & \multirow{2}{*}{$\begin{array}{l}\text { univariate } \\
\text { analysis } \\
p \text { value }\end{array}$} & \multicolumn{2}{|c|}{ multivariate analysis } & \multirow{2}{*}{$\begin{array}{l}\text { univariate } \\
\text { analysis } \\
p \text { value }\end{array}$} & \multicolumn{2}{|c|}{ multivariate analysis } \\
\hline & & HR (95\% CI) & $p$ value & & $\mathrm{HR}(95 \% \mathrm{CI})$ & $p$ value \\
\hline Age & $<0.001$ & $1.06(1.05-1.08)$ & $<0.001$ & $<0.001$ & $0.96(0.95-0.98)$ & $<0.001$ \\
\hline Male sex & $<0.001$ & $1.34(1.05-1.71)$ & 0.019 & 0.099 & $0.96(0.72-1.28)$ & 0.790 \\
\hline $\mathrm{DM}$ & $<0.001$ & $1.66(1.31-2.10)$ & 0.011 & $<0.001$ & $0.50(0.38-0.66)$ & $<0.001$ \\
\hline Hypertension & $<0.001$ & $1.24(0.97-1.60)$ & 0.089 & 0.026 & $0.87(0.63-1.21)$ & 0.402 \\
\hline Hyperlipidemia & 0.516 & & & 0.205 & & \\
\hline Body mass index & 0.274 & & & 0.419 & & \\
\hline Smoker & 0.174 & & & 0.213 & & \\
\hline PCI history & 0.269 & & & 0.433 & & \\
\hline MI history & 0.325 & & & 0.500 & & \\
\hline CVA history & $<0.001$ & $1.53(1.06-2.21)$ & 0.025 & 0.733 & & \\
\hline ACS & 0.316 & & & 0.782 & & \\
\hline LVEF & $<0.001$ & $0.97(0.96-0.98)$ & $<0.001$ & 0.466 & & \\
\hline Cardiogenic shock & 0.324 & & & 0.203 & & \\
\hline
\end{tabular}

CKD, chronic kidney disease; PCI, percutaneous coronary intervention; eGFR, estimated glomerular filtration rate; HR, hazard ratio; $\mathrm{CI}$, confidence interval; DM, diabetes mellitus; MI, myocardial infarction; CVA, cerebrovascular accident; ACS, acute coronary syndrome; LV EF, left ventricular ejection fraction.

group 2 patients with normal pre-PCI eGFR. Young age and no DM were significant predictors of kidney function recovery after PCI in group 3 and group 4 patients with abnormal pre-PCI eGFR.

When pre-PCI and post PCI eGFR were added to the clinical risk factors for predicting all-cause death and cardiac death, the model with post-PCI eGFR showed the highest C index $(0.749,95 \%$ CI [0.736-0.761]; 0.744, 95\% CI [0.731-0.756]) (Fig. 3). For cardiac death, the model with post-PCI eGFR showed significantly improved net reclassification improvement compared to the model with pre-PCI eGFR (Fig. 3).

\section{Discussion}

This study analyzed the prognostic implication of $f / u$ eGFR for patients undergoing PCI using the observation registry. The first finding was that the eGFR 3-6 months after PCI was more accurate for predicting patient outcomes than pre-PCI eGFR. The second finding was that the prognosis of patients with normal pre-PCI and abnormal f/u (at 3-6 months) renal function was worse than that of patients with abnormal pre-PCI and normal $\mathrm{f} / \mathrm{u}$ renal function. The third finding was that young age and no DM were significant predictors of recovery from initial renal dysfunction. Old age, male sex, DM, a CVA history, and a low LVEF were significant predictors of aggravated renal function.

It is widely known that pre-PCI renal function helps predict outcomes in PCI patients [7]. However, until now, no study has reported the prognosis of patients' renal function 3-6 months after PCI. This investigation is the first to evaluate prognosis using f/u eGFR. We also demonstrated the clinical outcomes of PCI according to renal function change in a large unrestricted population, i.e., that reflects real-world practice.

Several studies have shown that abnormal renal function pre-PCI correlates with the occurrence of adverse events. This result could be due to poor general vessel conditions in patients with poor renal function. This might be partly explained by conditions like age, DM, and hypertension [8]. In addition, kidney failure speeds up the development of atherosclerosis. Thus, such patients might have more extensive coronary and peripheral artery disease, such as multivessel disease [9].

Pre-PCI renal dysfunction might be temporarily caused by multifactorial factors, including an ischemic insult, in a healthy kidney. In other cases, CKD might have existed before. It might be further exacerbated by ischemia and 
Fig. 3. Receiver-operating characteristics curves for predicting all-cause death and cardiac death. Brier score, discriminant function (C index), net reclassification improvement (NRI), and integrated discrimination index (IDI) were compared in 3 models. The reference model included clinical risk factors only, including age, sex, hypertension, diabetes mellitus, hyperlipidemia, a history of myocardial infarction, a history of revascularization, and acute coronary syndrome. Brier score, C index, NRI, and IDI values of models with clinical risk factors only, and pre-PCI eGFR or post-PCIeGFR in addition to clinical risk factor were compared. Among these, the model with the post-PCI showed the highest $\mathrm{C}$ index, NRI, and IDI values in allcause death (a) and cardiac death (b). CI, confidence interval; eGFR, estimated glomerular filtration rate; PCI, percutaneous coronary intervention.

Prognostic Significance of $\mathrm{f} / \mathrm{u}$ eGFR in PCI Patients

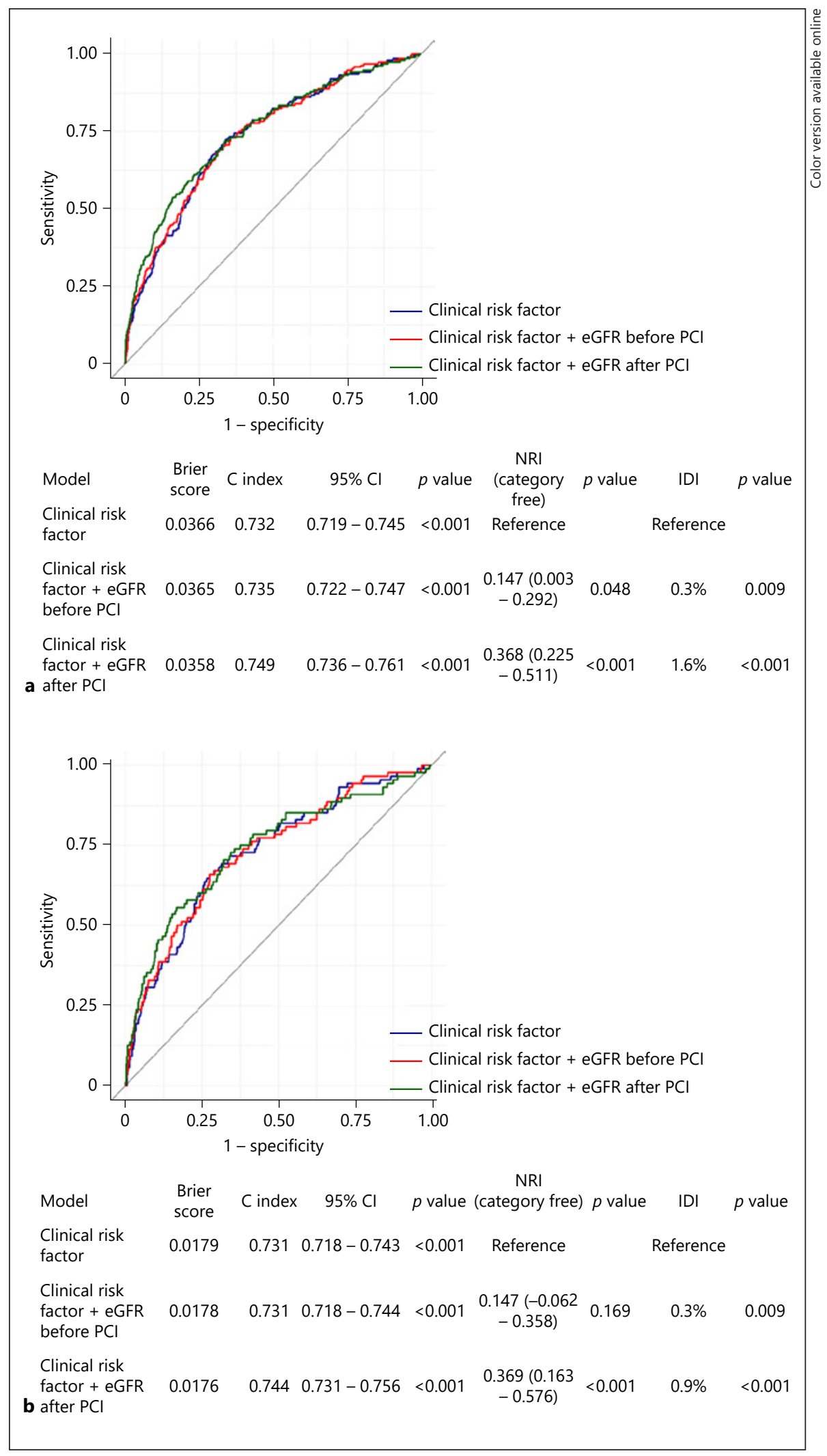

Cardiorenal Med 2021;11:77-85 
contrast medium [10]. In both instances, normal kidneys usually recover after the insult, but the abnormal CKD finding remains. Recovery takes several weeks to months. It usually takes less than three months to recover $[11,12]$. Kidney Disease Improving Global Outcomes (KDIGO) acute kidney injury (AKI) guidelines recommend that kidney function should be evaluated 3 months after an AKI episode to establish the presence and extent of CKD [13]. In this study, we used f/u eGFR after $>3$ months; we could thus differentiate CKD and AKI.

Group 1 had a lower rate of all-cause and cardiac death than the other groups. We compared group 2 and group 3 regarding renal function changes after PCI. After adjusting for all variables listed in Table 1, we found a higher risk of all-cause death in group 3, but not of cardiac death, recurrent MI, or TLR. The prognosis of a group with aggravation from normal renal function was worse than that of a group with recovery from abnormal renal function.

In our analysis, young age and no DM were significant predictors of recovery from the initial kidney injury. However, the renal function of group 3 recovered to within a normal range after 3-6 months; the kidneys of patients in group 3 were thought to be susceptible to acute insult and prone to acute renal failure. Initially considered fully reversible, recent evidence has suggested that these events may promote disease progression in the longer term [14]. Recently, it was established that even milder forms of AKI not requiring dialysis are associated with both short- and long-term mortality $[15,16]$. A previous CKD study showed no significant difference in the rate of TLR between CKD and non-CKD groups [17].

We found that predictive factors for the occurrence of CKD after PCI in group 1 and group 2 patients with normal pre-PCI eGFR were older age, male sex, DM, a CVA history, and a low LVEF. Recent studies have also shown that predictors of progression of CKD are old age, male sex, DM, heart failure, and stroke $[18,19]$. The results of our study thus coincide with those of recent studies.

Although the biological mechanism linking CKD progression after AKI, as in group 2, has not fully been elucidated, it has been postulated that a combination of acute endothelial damage that leads to vascular dropout and nephron loss, followed by glomerular hypertrophy with the development of fibrosis might play a role [20]. DM is the most important contributor to $\mathrm{CKD}$, and $\mathrm{DM}$ patients are at a greater risk of requiring hospitalization and experiencing AKI. Recent findings indicate that the rate of advanced CKD progression from AKI in DM patients is 3-fold higher than that in non-DM patients [21]. In terms of recovery from AKI, we found that younger nonDM young patients would recover.

When the scoring system was added to clinical risk factors, the model with the $\mathrm{f} / \mathrm{u}$ eGFR showed the highest $\mathrm{C}$ index for all-cause death and cardiac death. In addition, f/u eGFR got better net reclassification improvement for both all-cause death and cardiac death when added to clinical risk factors. These results imply that $\mathrm{f} / \mathrm{u}$ renal function can estimate patient risk after PCI better than pre-PCI renal function can. We recommend checking $\mathrm{f} / \mathrm{u}$ eGFR after 3 months to predict the prognosis of patients undergoing $\mathrm{PCI}$ in clinical practice. In conclusion, $\mathrm{F} / \mathrm{U}$ Post-PCI eGFR was more accurate for predicting patient outcomes than pre-PCI eGFR.

Our study has several limitations. First, we used a nonrandomized, retrospective design. This might have affected our results due to allocation bias, uneven distribution of risk factors, and the possibility of unmeasured confounders. Second, we excluded some patients without information about f/u eGFR level after the procedure, which may have contributed to selection bias. Third, baseline CKD and prerenal AKI may have different implications in terms of prognosis. We checked only one eGFR value before PCI. A single-point value of eGFR could be affected by fluctuations due to hemodynamic factors, medication, etc. This could have caused misclassification, especially in patients with pre-PCI abnormal eGFR.

\section{Statement of Ethics}

Our Institutional Review Board approved this study. Informed consent was waived due to the retrospective nature of the study.

\section{Conflict of Interest Statement}

The authors declare that no conflict of interest exists.

\section{Funding Source}

This work received no funding or other financial support.

\section{Author Contributions}

Dong-Bin Kim and Won Jik Lee participated in conceptualization, data curation, and formal analysis of data. Sung-Ho Her participated in visualization. Chul-Soo Park, Hee-Yeol Kim, JongMin Lee, and Wook Sung Chung participated in supervision. Dong-Bin Kim is the corresponding author. 


\section{References}

1 Go AS, Chertow GM, Fan D, McCulloch CE, Hsu CY. Chronic kidney disease and the risks of death, cardiovascular events, and hospitalization. N Engl J Med. 2004 Sep;351(13): 1296-305

2 Mathew RO, Bangalore S, Lavelle MP, Pellikka PA, Sidhu MS, Boden WE, et al. Diagnosis and management of atherosclerotic cardiovascular disease in chronic kidney disease: a review. Kidney Int. 2017 Apr;91(4):797807.

3 Muntner P, He J, Hamm L, Loria C, Whelton $P K$. Renal insufficiency and subsequent death resulting from cardiovascular disease in the United States. J Am Soc Nephrol. 2002 Mar; 13(3):745-53.

4 Levey AS, Coresh J, Greene T, Stevens LA, Zhang YL, Hendriksen S, et al.; Chronic Kidney Disease Epidemiology Collaboration. Using standardized serum creatinine values in the modification of diet in renal disease study equation for estimating glomerular filtration rate. Ann Intern Med. 2006 Aug;145(4):24754.

5 National Kidney Foundation. K/DOQI clinical practice guidelines for chronic kidney disease: evaluation, classification, and stratification. Am J Kidney Dis. 2002 Feb;39(2 Suppl 1):S1-266.

6 Pencina MJ, D’Agostino RB Sr, D’Agostino RB Jr, Vasan RS. Evaluating the added predictive ability of a new marker: from area under the ROC curve to reclassification and beyond. Stat Med. 2008 Jan;27(2):157-72.

7 Morel O, El Ghannudi S, Jesel L, Radulescu B, Meyer N, Wiesel ML, et al. Cardiovascular mortality in chronic kidney disease patients undergoing percutaneous coronary intervention is mainly related to impaired $\mathrm{P} 2 \mathrm{Y} 12$ inhibition by clopidogrel. J Am Coll Cardiol. 2011 Jan;57(4):399-408.

8 Sarnak MJ, Levey AS, Schoolwerth AC, Coresh J, Culleton B, Hamm LL, et al.; American Heart Association Councils on Kidney in
Cardiovascular Disease, High Blood Pressure Research, Clinical Cardiology, and Epidemiology and Prevention. Kidney disease as a risk factor for development of cardiovascular disease: a statement from the American Heart Association Councils on Kidney in Cardiovascular Disease, High Blood Pressure Research, Clinical Cardiology, and Epidemiology and Prevention. Circulation. 2003 Oct; 108(17):2154-69.

9 Yagi H, Kawai M, Komukai K, Ogawa T, Minai K, Nagoshi T, et al. Impact of chronic kidney disease on the severity of initially diagnosed coronary artery disease and the patient prognosis in the Japanese population. Heart Vessels. 2011 Jul;26(4):370-8.

10 Tumlin J, Stacul F, Adam A, Becker CR, Davidson C, Lameire N, et al.; CIN Consensus Working Panel. Pathophysiology of contrastinduced nephropathy. Am J Cardiol. 2006 Sep;98(6 6A):14K-20K.

11 Heung M, Steffick DE, Zivin K, Gillespie BW, Banerjee T, Hsu CY, et al.; Centers for Disease Control and Prevention CKD Surveillance Team. Acute Kidney Injury Recovery Pattern and Subsequent Risk of CKD: An Analysis of Veterans Health Administration Data. Am J Kidney Dis. 2016 May;67(5):742-52.

12 Forni LG, Darmon M, Ostermann M, Oudemans-van Straaten HM, Pettilä V, Prowle JR, et al. Renal recovery after acute kidney injury. Intensive Care Med. 2017 Jun;43(6):855-66.

13 Ad-hoc working group of ERBP; Fliser D, Laville M, Covic A, Fouque D, Vanholder R, et al. A European Renal Best Practice (ERBP) position statement on the Kidney Disease Improving Global Outcomes (KDIGO) clinical practice guidelines on acute kidney injury: part 1: definitions, conservative management and contrast-induced nephropathy. Nephrol Dial Transplant. 2012 Dec; 27(12):4263-72

14 Chawla LS, Amdur RL, Shaw AD, Faselis C, Palant CE, Kimmel PL. Association between
$\mathrm{AKI}$ and long-term renal and cardiovascular outcomes in United States veterans. Clin J Am Soc Nephrol. 2014 Mar;9(3):448-56.

15 Lai CF, Wu VC, Huang TM, Yeh YC, Wang KC, Han YY, et al.; National Taiwan University Hospital Study Group on Acute Renal Failure (NSARF). Kidney function decline after a non-dialysis-requiring acute kidney injury is associated with higher long-term mortality in critically ill survivors. Crit Care. 2012 Jul;16(4):R123.

16 Pannu N, James M, Hemmelgarn B, Klarenbach S; Alberta Kidney Disease Network. Association between AKI, recovery of renal function, and long-term outcomes after hospital discharge. Clin J Am Soc Nephrol. 2013 Feb;8(2):194-202.

17 Lee JM, Kang J, Lee E, Hwang D, Rhee TM, Park J, et al. Chronic Kidney Disease in the Second-Generation Drug-Eluting Stent Era: Pooled Analysis of the Korean Multicenter Drug-Eluting Stent Registry. JACC Cardiovasc Interv. 2016 Oct;9(20):2097-109.

18 Liaño F, Felipe C, Tenorio MT, Rivera M, Abraira V, Sáez-de-Urturi JM, et al. Longterm outcome of acute tubular necrosis: a contribution to its natural history. Kidney Int. 2007 Apr;71(7):679-86.

19 Go AS, Yang J, Tan TC, Cabrera CS, Stefansson BV, Greasley PJ, et al.; Kaiser Permanente Northern California CKD Outcomes Study. Contemporary rates and predictors of fast progression of chronic kidney disease in adults with and without diabetes mellitus. BMC Nephrol. 2018 Jun;19(1):146.

20 Basile DP. The endothelial cell in ischemic acute kidney injury: implications for acute and chronic function. Kidney Int. $2007 \mathrm{Jul}$; 72(2):151-6.

21 Thakar CV, Christianson A, Himmelfarb J, Leonard AC. Acute kidney injury episodes and chronic kidney disease risk in diabetes mellitus. Clin J Am Soc Nephrol. 2011 Nov; 6(11):2567-72. 